\title{
2,4 Dinitrophenol - A Danger for Patients with Drug Use Issues and Eating Disorders Alike
}

\section{Thomas I Lemon*}

University Hospital of Wales, Cardiff CF14 4XW, UK

\section{Dear Sir,}

Whilst there has always been a section of society with an excessive interest in the way they look, of late there has been an increase of medications available to these people to assist this motive. Whilst it is normal for people to have an interest in the way they look, unfortunately the drugs currently available may encourage people suffering body dysmorphia to use these drugs to excess. This is a concern as overdose of these gym drugs can lead to death.

2,4 Dinitrophenol works as a protonophore by carrying protons across the mitochondrial membrane and hence uncoupling oxidative phosphorylation [1] effectively through making ATP less efficient, cellular respiration energy is wasted as heat. As the doses increase, energy production becomes more inefficient, the metabolic rate increases (which causes the fat loss) in order to meet energy demands. It is the excessive rise in body temperature that causes the deaths, indeed case reports show acute administration of $25-50 \mathrm{mg} / \mathrm{kg}$ can be fatal [2] This however has not stopped bodybuilders and athletes using it.

It is of paramount importance that all drug use is assessed in people with potential or diagnosed eating disorders. There is now a new risk to these vulnerable patients in these gym drugs, to which an addiction would only perpetuate their problems.

\section{References}

1. Harper JA, Dickinson K, Brand MD (2001) "Mitochondrial uncoupling as a target for drug development for the treatment of obesity". Obesity reviews: an official journal of the International Association for the Study of Obesity 2: 255-265.

2. 2. Hsiao AL, Santucci KA, Seo-Mayer P, Mariappan MR, Hodsdon ME, et al. (2005) "Pediatric fatality following ingestion of dinitrophenol: postmortem identification of a "dietary supplement". ClinToxicol (Phila) 43: 281-285.
*Corresponding author: Dr. Thomas I Lemon, University Hospital of Wales, Cardiff CF14 4XW, UK, E-mail: lemonti@cf.ac.uk

Received April 08, 2013; Accepted May 28, 2013; Published May 30, 2013

Citation: Lemon TI (2013) 2,4 Dinitrophenol - A Danger for Patients with Drug Use Issues and Eating Disorders Alike. J Sports Med Doping Stud 3: 121.

Copyright: ( 2013 Lemon TI. This is an open-access article distributed under the terms of the Creative Commons Attribution License, which permits unrestricted use, distribution, and reproduction in any medium, provided the original author and source are credited. 